\title{
Lidil
}

Revue de linguistique et de didactique des langues

$62 \mid 2020$

Recherches actuelles en didactique du lexique: avancées, réflexions, méthodes

\section{Alain Rabatel et Laurence Rosier (coord.), Le discours et la langue. Revue de linguistique française et d'analyse du discours, tome 11.1: Les défis de l'écriture inclusive}

Louvain-la-Neuve, EME Éditions, 2019, 187 p.

\section{Mireille Baurens}

\section{OpenEdition}

Édition électronique

URL : http://journals.openedition.org/lidil/8246

DOI : $10.4000 /$ lidil.8246

ISSN : 1960-6052

Éditeur

UGA Éditions/Université Grenoble Alpes

\section{Édition imprimée}

ISBN : 978-2-37747-226-0

ISSN : $1146-6480$

Référence électronique

Mireille Baurens, « Alain Rabatel et Laurence Rosier (coord.), Le discours et la langue. Revue de linguistique française et d'analyse du discours, tome 11.1 : Les défis de l'écriture inclusive », Lidil [En ligne], 62 | 2020, mis en ligne le 03 novembre 2020, consulté le 05 novembre 2020. URL : http:// journals.openedition.org/lidil/8246; DOI : https://doi.org/10.4000/lidil.8246

Ce document a été généré automatiquement le 5 novembre 2020.

(c) Lidil 


\title{
Alain Rabatel et Laurence Rosier (coord.), Le discours et la langue. Revue de linguistique française et d'analyse du discours, tome 11.1 : Les défis de l'écriture inclusive
}

Louvain-la-Neuve, EME Éditions, 2019, 187 p.

\author{
Mireille Baurens
}

\section{RÉFÉRENCE}

Alain Rabatel et Laurence Rosier (coord.), Le discours et la langue. Revue de linguistique française et d'analyse du discours, tome 11.1 : Les défis de l'écriture inclusive, Louvain-laNeuve, EME Éditions, 2019, 187 p.

1 Le tome 11.1 (2019) de la Revue de linguistique française et d'analyse du discours : Le discours et la langue, est intitulé Les défis de l'écriture inclusive; il est coordonné par Alain Rabatel (professeur de l'université Lyon 1, laboratoire ICAR) et Laurence Rosier (Université libre de Belgique, laboratoire Ladisco/striges) et comporte neuf articles, allant de 12 à 36 pages dans un ensemble de 189 pages (propos introductif de 8 pages). Les auteurs convoqués sont variés dans leur ancrage disciplinaire et géographique et leurs points de vue complémentaires voire contrastés. Une liberté éditoriale formelle laisse les auteur-es choisir leur façon d'inscrire le féminin aussi dans leurs écrits ; tirets, points médians, doublets alternent, non sans quelques incohérences formelles («le.la citoyen.ne » précède «le.la locuteur-trice », p. 42-43). Est ainsi signifiée la liberté de se situer dans la discussion et la liberté d'usage de chacun-e.

2 Tous les articles méritent une attention particulière pour leur observation précise de ce qui est «questionnable », « pensable », « incarné », « conceptualisé » dans le discours, 
par rapport au français inclusif (p. 71). Deux articles posent les balises du propos : l'un, Bernard Cerquiglini, définit un consensus éthique, la règle du masculin renvoie à la représentation dévalorisée, la norme de l'occultation des femmes; l'autre, Alpheratz, grammairienne, envisage la création du genre neutre en français. D'emblée, le propos introductif valide : «Si l'écriture inclusive est largement une affaire de militants, cela peut-être aussi et en même temps, une affaire de linguistes éclair.é.s!»(p. 8) La variabilité lexicale est frappante: évènement linguistique, écriture inclusive, neutralisation de la langue, appropriation de la langue, vision dominante de la langue légitime (portée par l'Académie, amplement citée pour sa polémique virulente, incohérente et changeante), l'abondance terminologique montre à la fois la difficulté de savoir ce qui est en jeu (malgré le titre accentuant l'écriture, nombre d'articles évoquent l'oral à prendre en compte) et l'intrinsèque pluralité des visées: de quoi parle-t-on ? Pourquoi en parler? Que s'agit-il d'envisager ou pas après en avoir parlé ?

Entre inéluctables changements (qui "hérissent» (p.7), Laurence Rosier illustre les violences verbales en lien avec les enjeux idéologiques d'une polémique résurgente), nécessaire posture éthique, recadrage historique et linguistique ravivant ou contrant la neutralité du masculin dit générique, impact des représentations psycho-sociolinguistiques sur l'évolution du traitement du féminin en français, comparaisons interculturelles (Laure Gardelle déroule un face-à-face précis entre l'usage du féminin en anglais et en français), mise en relief de la stabilité canadienne, surlignage de la féminisation en Suisse (Daniel Elmiger, Eva Schaeffer-Lacroix et Verena Tunger exemplifient les diversités de rédaction non sexiste, entre les langues du pays et entre les cantons et le cadrage fédéral), la revue est exemplaire dans l'amplitude qu'elle offre du débat.

4 En termes sociologiques et philosophiques, un socle éthique pose le langage comme instrument de domination, d'occultation de la part des femmes qui doit être questionné au regard de leur nécessaire valorisation. Dans une perspective historique, deux points de vue sont illustrés. L'usage a prouvé l'existence du féminin et donc sa possibilité dans le langage ; l'usage a prouvé que ce que l'on considère comme le masculin et que l'on qualifie de générique (à tort aux yeux d'un grand nombre) est historiquement neutre (dans sa démonstration, Dan Van Raemdonk convoque le terme de "genre non marqué » pour qualifier le masculin qui donc ne l'emporterait plus...). Enfin, les perspectives pragmatiques ne manquent pas et parsèment les différentes contributions, de leurs... différences, entre doublets occasionnels, illustrations spécifiques sur les femmes, alternances, suppression des formes genrées, indifférenciation, ainsi habilement résumées par Laure Gardelle : il s'agit de varier les procédés (p. 184).

5 La notion de « justice » convoquée par Jean-Marie Klinkenberg ouvre le propos collectif et en cristallise l'essence: les techniques de rédaction non sexistes ne peuvent être réduites à la polémique portant sur des arguments linguistiques qu'elles ont suscités. L'écriture inclusive cherche à inclure, sa visée est politique et démocratique. L'état démocratique doit avoir pour objectif de réduire l'exclusion, en particulier celle des femmes. Le mot d'ordre d'une politique linguistique doit être la visibilisation langagière, gage d'inclusion qui reste l'objectif lointain à atteindre. Alpheratz énonce ainsi que "l'inclusivité linguistique de genre se constate internationalement» et annonce que cette inclusivité "sort les langues de la sphère de l'idiolecte", et rassemble autour d'une " éthique en lutte contre toutes les discriminations » (p. 72), où 
le genre masculin en emploi générique n'est plus le paradigme, mais «l'anomalie » (p. 73).

6 Il convient de souligner deux points faibles à mon sens. Tout d'abord, des chercheur-es majeur-es sont exclus de la sélection, comme Éliane Viennot citée plusieurs fois par les participant-es et incontournable par ses nombreux travaux sur la communication inclusive, ou encore Claudie Baudino elle aussi citée, dont la thèse Politique de la langue et différence sexuelle : la politisation du genre des noms de métier (Paris, L'Harmattan, 2001) a été l'un des tremplins de la mise au jour des complexités du débat. Feu Anne-Marie Houdebine, sociolinguiste, aurait pu avoir une place particulière face à son engagement scientifique dès le début du débat. Notons que ces trois chercheures défendent l'usage du féminin. Par ailleurs, il aurait été intéressant d'avoir une présentation succincte des différents auteur-es.

\section{AUTEURS}

\section{MIREILLE BAURENS}

LIDILEM (EA 609), Université Grenoble Alpes 